\section{Popular uprising spreads science}

Hundreds of young Arab people are establishing initiatives to promote science in Arabic and raise scientific literacy across the Middle East, free of the censorship and bureaucracy of government and religious authorities (see Nature Middle East http://doi.org/7p8; 2015).

They are publishing and translating scientific news and articles every day, including on topics such as evolution and sex education, which are widely taboo in many parts of the Middle East. Tens of thousands of reports, videos and infographics are popularizing a more objective way of thinking in the region.

The movement relies on crowdsourcing from a vast pool of educated volunteers who are supervised by local scientists.

This 'uprising' has reached millions of people in a relatively short time. One sciencecommunication group, Syrian Researchers, celebrated its millionth follower on Facebook in mid-2015 (www.syr-res.com). Another group, Scientific Saudi (www.scientificsaudi.com), has more than 250,000 social-media followers and is a learning partner of the Arabic edition of the MIT Technology Review. Muath Alduhishy University of Queensland, Herston, Australia. Mouhannad Malek Babraham Institute, Cambridge, UK. dr.alduhishy@gmail.com

\section{Citizen projects can minimize conflicts}

Well-structured schemes for citizen scientists can minimize the potential for conflicts of interest (Nature 524, 265; 2015).

Projects such as the UK Breeding Bird Survey (go.nature. com/keyvpu), run by the British Trust for Ornithology, use volunteer-friendly protocols and specify sampling at representative locations to standardize volunteer commitment. The primary motivator for observers is then whether to invest and participate in the survey, not whether they can influence which data are recorded.

Citizen scientists participating in well-structured schemes are more likely to deliver costeffective monitoring on a large scale and to improve societal understanding of scientific issues. James W. Pearce-Higgins British Trust for Ornithology, Thetford, UK.

james.pearce-higgins@bto.org

\section{Resolve ambiguities in China's emissions}

As the former chair of the Consultative Group of Experts organized by the United Nations Framework Convention on Climate Change (UNFCCC) to help developing countries to produce carbon-emission inventories, I question the claim that China's emissions from coal have been overestimated (see Nature 524, 276; 2015 and Z. Liu et al. Nature 524, 335-338; 2015).

The accuracy of estimates depends largely on emissionfactor estimates for the coal China uses (emission factor is the amount of carbon oxidized per unit of fuel consumed). For example, Liu and colleagues report emission factors that were estimated from the average carbon content of a range of highquality to low-quality Chinese coal types. They write that these emission factors are $40 \%$ below the default values recommended by the 2006 guidelines of the Intergovernmental Panel on Climate Change (IPCC). However, I find their comparison flawed because the IPCC factor they use derives from coking coal, which contains more carbon and so has a higher emission factor than an 'average' coal type.

Furthermore, the conclusion by Liu et al. that China's fossilfuel use in 2000-12 exceeded official figures by $10 \%$ seems incompatible with the authors' estimated emissions being $12 \%$ lower than those calculated by the Chinese government. The official team's higher estimate was based on information from China's coal-quality database and from coal-trading contracts.

Such ambiguities call for clear resolution so that estimates of China's emissions are accurately conveyed.

Fei Teng Tsinghua University, Beijing, China.

tengfei@tsinghua.edu.cn

\section{Overhaul rules for hazardous chemicals}

The huge chemical explosion at the Chinese port of Tianjin on 12 August is another in the country's long list of industrial accidents involving chemicals. In 2010-14, more than 2,000 people were killed in 326 such accidents (J. Ren and Y. Mu Chem. Enterp. Manag. 16, 28-31; 2015; in Chinese), calling into question the adequacy and enforcement of national regulations for the safe management of hazardous chemicals.

China needs better legislation and more detailed regulations for controlling risk at different stages in the life cycle of hazardous chemicals. Safety supervision must be made more effective, for example by drawing up regulations modelled on the European Union's Seveso Directive for industrial accidents (see go.nature. com/zyjp85). Supervision is currently disorderly, overseen by a fragmented and overlapping structure of multiple agencies, including the State Administration of Work Safety and the ministries of transport, public security, environmental protection, agriculture and health.

Effective enforcement of China's safety management of hazardous chemicals may be foiled by the limited expertise of company front-line managers (M. Liu et al. Contemp. Chem. Ind. 43, 2661-2662; 2014; in Chinese). More data are needed on the nature, handling and storage of the chemicals themselves so that risks can be properly assessed and managed (see go.nature.com/bzsydq). Zhenwu Tang North China Electric Power University, Beijing, China.

Qifei Huang, Yufei Yang

Chinese Research Academy of

Environmental Sciences, Beijing, China.

huangqf@craes.org.cn

\section{Olympics will make water scarcity worse}

The 2022 Winter Olympics in Beijing threaten to seriously exacerbate water shortages in the area, where the available water per person is already only about $3 \%$ of the world's average (see also Nature 524, 278-279; 2015).

The Winter Olympics will take place in February, when monthly precipitation in Beijing is less than 6 millimetres, so the games will need to rely exclusively on artificial snow (see go.nature.com/bkxbo8). This will entail pumping massive volumes of water out of reservoirs and rivers, further reducing the local population's water supply, and using huge amounts of energy to cool this water to make ice crystals that can be ejected. For example, producing artificial snow for winter sports in Beijing in 2010 used the annual equivalent of the water and electricity consumed by 8,300 and 5,400 households, respectively (see go.nature.com/ ysdpbd; in Chinese).

Hong Yang University of Oslo, Norway.

Julian R. Thompson, Roger J. Flower University College London, UK.

hongyanghy@gmail.com

CONTRIBUTIONS

Correspondence may be sent to correspondence@ nature.com after consulting go.nature.com/cmchno. 